\title{
Guidance on the management of familial hypercholesterolaemia in Hong Kong: an expert panel consensus viewpoint
}

\author{
Brian Tomlinson *, Juliana CN Chan, WB Chan, Walter WC Chen, Francis CC Chow, SK Li, \\ Alice PS Kong, Ronald CW Ma, David CW Siu, Kathryn CB Tan, Lawrence KS Wong, Vincent TF Yeung, \\ Betty WM But, PT Cheung, CC Fu, Joanna YL Tung, WC Wong, HC Yau
}

\begin{abstract}
A B S T R A C T
In 2016, meetings of groups of physicians and paediatricians with a special interest in lipid disorders and familial hypercholesterolaemia were held to discuss several domains of management of familial hypercholesterolaemia in adults and children in Hong Kong. After reviewing the evidence and guidelines for the diagnosis, screening, and management of familial hypercholesterolaemia, consensus was reached on the following aspects: clinical features, diagnostic criteria, screening in adults, screening in children, management in relation to target plasma low-density lipoprotein cholesterol levels, detection of atherosclerosis, lifestyle and behaviour modification, and pharmacotherapy.
\end{abstract}

\section{Hong Kong Med J 2018;24:408-15 \\ DOI: 10.12809/hkmj187215}

\footnotetext{
${ }^{1}$ B Tomlinson *, MB, BS, MD

1 JCN Chan, MB, ChB, MD

${ }^{2}$ WB Chan, MB, ChB, FHKAM (Medicine)

${ }^{3}$ WWC Chen, MD, FACC

${ }^{1}$ FCC Chow, MB, BS

${ }^{4} \mathrm{SK}$ Li, FRCP (Lond), FACC

${ }^{1}$ APS Kong, FRCP, MD

${ }^{1}$ RCW Ma, FHKCP, FHKAM (Medicine)
}

\author{
${ }^{5}$ DCW Siu, MB, BS, MD \\ ${ }^{5} \mathrm{KCB}$ Tan, MBBCH, MD \\ ${ }^{1}$ LKS Wong, FRCP (Lond), MD \\ ${ }^{6}$ VTF Yeung, FHKAM (Medicine), MD \\ ${ }^{7}$ BWM But, MB, BS, FHKAM (Paediatrics) \\ ${ }^{8}$ PT Cheung, FRCP (Edin), FHKCPaed \\ ${ }^{9} \mathrm{CC}$ Fu, MB, ChB, FHKAM (Paediatrics) \\ ${ }^{10}$ JYL Tung, MB, BS, FHKAM (Paediatrics) \\ ${ }^{11}$ WC Wong, FHKAM (Paediatrics), FHKCPaed \\ ${ }^{12}$ HC Yau, FHKCPaed, FHKAM (Paediatrics)
}

${ }^{1}$ Department of Medicine and Therapeutics, The Chinese University of Hong Kong, Shatin, Hong Kong

2 Qualigenics Diabetes Centre, Hong Kong

${ }^{3}$ The Heart Clinic, Hong Kong

${ }^{4}$ Premier Medical Center, Hong Kong

5 Department of Medicine, The University of Hong Kong, Pokfulam, Hong Kong

${ }^{6}$ Department of Medicine and Geriatrics, Our Lady of Maryknoll Hospital, Wong Tai Sin, Hong Kong

7 Department of Paediatrics, Queen Elizabeth Hospital, Jordan, Hong Kong

3 Town Health International Health Management Centre, Hong Kong

${ }^{9}$ Department of Paediatrics and Adolescent Medicine, Princess Margaret Hospital, Laichikok, Hong Kong

${ }^{10}$ Department of Paediatrics and Adolescent Medicine, The University of Hong Kong, Pokfulam, Hong Kong

${ }^{11}$ Department of Paediatrics and Adolescent Medicine, Alice Ho Miu Ling Nethersole Hospital, Tai Po, Hong Kong

${ }^{12}$ Department of Paediatrics, Prince of Wales Hospital, Shatin, Hong Kong

* Corresponding author: btomlinson@cuhk.edu.hk

\section{Introduction}

Familial hypercholesterolaemia (FH), an autosomal codominant inherited disorder of lipoprotein metabolism, is characterised by markedly elevated plasma low-density lipoprotein cholesterol (LDL-C) levels and increased risk of premature atherosclerotic cardiovascular disease (CVD), particularly coronary heart disease (CHD).$^{1-3}$ Familial hypercholesterolaemia is generally caused by mutations in the genes related to the LDL receptor (LDLR) pathway (eg, loss-of-function mutations in the $L D L R$ or apolipoprotein $\mathrm{B}(\mathrm{apoB})$ gene $(A P O B)$ or gain-of-function mutations in the proprotein convertase subtilisin-kexin type 9 [PCSK9] gene) resulting in marked elevation of plasma LDL-C levels from birth.

Heterozygous (He) $\mathrm{FH}$ is one of the most common human genetic disorders. It affects 1 in 200 to 300 individuals in unselected general populations. The prevalence of homozygous (Ho) FH has been estimated at 1 in 1000000 , based on a frequency of 1 in 500 for $\mathrm{HeFH}$, but it is likely to be more common. ${ }^{1,4}$ Familial hypercholesterolaemia is associated with considerable morbidity and mortality because of CHD. If left untreated, men and women with $\mathrm{HeFH}$ typically develop CHD before the ages of 55 and 60 years, respectively; $50 \%$ of men and $15 \%$ of women die before these ages, whereas those with HoFH may develop CHD very early in life. ${ }^{1}$

Early identification and optimal treatment of patients with $\mathrm{FH}$ are crucial for the prevention of atherosclerosis progression and coronary complications. Although $\mathrm{FH}$ is a very common genetic disorder, it remains largely undetected and undertreated. ${ }^{1}$ Recent guidelines and consensus statements in Europe and in some Asia- 
Pacific countries highlight the need for the early identification of $\mathrm{FH}$ to improve the awareness and management of this condition. ${ }^{1,4-7}$

As in most other countries, ${ }^{8}$ there are significant gaps in the awareness and management of FH among physicians and the general public in Hong Kong. There is no clear management guideline or consensus statement for $\mathrm{FH}$ in Hong Kong. On 22 February 2016, 12 experts on lipid disorders in Hong Kong convened for the local Advisory Board Meeting on the Management of Familial Hypercholesterolaemia in Hong Kong; and on 14 December 2016, 10 experts convened for a second meeting specifically regarding the management of paediatric patients with $\mathrm{FH}$ in Hong Kong. The principal objectives were to discuss the evidence for diagnosis, screening, and management of $\mathrm{FH}$, in order to develop a consensus statement relevant to Hong Kong. The panel reviewed both international guidelines and those for individual Asia-Pacific countries, then developed a consensus treatment matrix/guide regarding the diagnosis, screening, and management of FH. The expert panel discussed each issue until they had attained a unanimous consensus.

\section{Clinical features of familial hypercholesterolaemia in Hong Kong}

Plasma LDL-C levels in the Hong Kong general population are comparable to those of some Western countries., ${ }^{910}$ According to the experts' clinical experience, patients with FH in Hong Kong, especially older adults, tend to exhibit CVD later in life (approximately 70 years of age), compared with patients in Western countries. Many older patients with $\mathrm{FH}$ in Hong Kong are free of cardiovascular events in their 70 s or $80 \mathrm{~s}$; this may be related to their previously healthy lifestyle (eg, substantial physical activity with a healthy diet). However, young patients with $\mathrm{FH}$ tend to develop CVD at an earlier age than older patients within the same families. More recently, cardiovascular events have been observed in patients who are in their mid-20s. The increased risk in these young patients is likely due to lifestyle changes in the younger generations. Stroke remains uncommon in patients with $\mathrm{FH}$ in Hong Kong, presumably because elevated LDL-C levels are not a strong risk factor for cerebrovascular diseases. ${ }^{11}$

Clinical characteristics have been reported for 252 Hong Kong Chinese patients from 87 pedigrees who were clinically diagnosed with FH during 19902000 (mean [standard deviation] age 37 [17] years, including 43 patients aged $<18$ years). ${ }^{10}$ The mean plasma LDL-C level was $7.2(1.5) \mathrm{mmol} / \mathrm{L} .{ }^{10}$ Tendon xanthomata was present in $40.6 \%$ of males and $54.8 \%$ of females. The prevalence of known CHD was relatively low: $9.9 \%$ in males and $8.5 \%$ in females. ${ }^{10}$
香港家族性高膽固醇血症管理指引：專家組共識

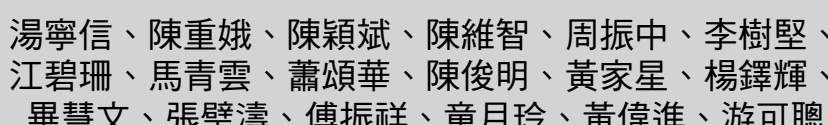

畢慧文、張璧濤、傅振祥、童月玲、黃偉進、游可聰

兩組包括治療血脂異常及家族性高膽固醇血症的專家和兒科專科醫生 在2016年舉行兩次會議, 討論香港患有家族性高膽固醇血症的成年人 和兒童的多方面管理。在回顧家族性高膽固醇血症的診斷、篩查和管 理的臨床數據及指引後, 他們就家族性高膽固醇血症的管理在下列方 面達成共識, 包括臨床特徵、診斷標準、成人篩查、兒童篩查、管理 血液低密度脂蛋白膽固醇的目標, 動脈粥樣硬化的檢測、生活方式和 行為改變, 以及藥物治療

\section{Diagnostic criteria of familial hypercholesterolaemia}

Although $\mathrm{FH}$ is generally considered to be a monogenic condition, it is typically diagnosed on the basis of clinical features and family history, rather than a genetic test. There are several sets of clinical criteria for diagnosing FH (Table $1^{7,12-15}$ ), including the Simon Broome Register diagnostic criteria, ${ }^{12}$ the Make Early Diagnosis to Prevent Early Deaths (MEDPED) criteria $^{13}$ and the Dutch Lipid Clinic Network Diagnostic Criteria ${ }^{14}$ (DLCNC; online supplementary Appendix); however, none of these are universally accepted as the best approach. More recently, Japanese experts have developed specific criteria for the diagnosis of $\mathrm{FH}$ in Japan. ${ }^{7}$

The $\mathrm{DLCNC}^{14}$ use a point system to assess the following characteristics: family history of $\mathrm{FH}$, history of premature CVD, physical examination of tendinous xanthomata and premature arcus cornealis, LDL-C levels, and DNA analysis. There is a point score for each item; a total point score of $>8$ is regarded as definite $\mathrm{FH}, 6$ to 8 as probable $\mathrm{FH}, 3$ to 5 as possible $\mathrm{FH}$, and $<3$ as unlikely FH. Similar to the DLCNC, the Simon Broome criteria ${ }^{12}$ use family history of $\mathrm{FH}$, physical signs (excluding arcus cornealis), LDL-C levels, and genetic tests to predict the probability of the diagnosis of FH. The MEDPED criteria $^{13}$ rely on plasma total cholesterol and LDL-C levels in the probands and their family members, without consideration of other phenotypes. The MEDPED criteria have a higher sensitivity, but lower specificity than the Dutch and Simon Broome diagnostic criteria. The Japanese FH criteria, ${ }^{16}$ which are similar to the Simon Broome criteria, use a population-specific LDL-C level $>4.7 \mathrm{mmol} / \mathrm{L}$ for adults and $>3.6 \mathrm{mmol} / \mathrm{L}$ for children as a criterion for the diagnosis of $\mathrm{FH}$.

The Dutch criteria were developed from patients who had been genotyped; thus, these comprise the only set of criteria validated by genetic tests. The panel agreed to apply the Dutch criteria for 
TABLE I. Comparison of diagnostic criteria for familial hypercholesterolaemia ${ }^{7,12-15}$

\begin{tabular}{|c|c|c|c|c|}
\hline Criteria set & DLCNC $^{14}$ & $\begin{array}{l}\text { Simon Broome Register } \\
\text { diagnostic criteria }^{12}\end{array}$ & MEDPED criteria ${ }^{13}$ & Japanese FH criteria $^{7}$ \\
\hline $\begin{array}{l}\text { Family history of premature } \\
\text { CVD or elevated cholesterol }\end{array}$ & $\checkmark$ & $\checkmark$ & $\checkmark$ & $\checkmark$ \\
\hline History of premature CVD & $\checkmark$ & $x$ & $x$ & $x$ \\
\hline $\begin{array}{l}\text { Physical signs and symptoms } \\
\text { (eg, tendon xanthoma) }\end{array}$ & $\checkmark$ & $\checkmark$ & $x$ & $\checkmark$ \\
\hline LDL-C cut-off level (mmol/L) & $\begin{array}{ll}\text { - } & \geq 8.5 \mathrm{mmol} / \mathrm{L}: 8 \text { points } \\
\text { - } & 6.5-8.4 \mathrm{mmol} / \mathrm{L}: 5 \text { points } \\
\text { - } & 4.0-4.9 \mathrm{mmol} / \mathrm{mmol} 3 \text { points } \\
\text { point }\end{array}$ & $\begin{array}{l}\text { - Adult: }>4.9 \\
\text { - } \text { Children }>4.0\end{array}$ & $\begin{array}{l}\text { - Specific levels based on } \\
\text { individual's age and a } \\
\text { family history of } \mathrm{FH}\end{array}$ & $\begin{array}{l}\text { - For HeFH: Adult: }>4.7 \\
\text { Children: }>3.6 \\
\text { - For HoFH: Total } \\
\text { cholesterol: }>15.5 \mathrm{mmol} / \mathrm{L}\end{array}$ \\
\hline DNA analysis & $\checkmark$ (optional) & $\checkmark$ (optional) & $x$ & $x$ \\
\hline Possible diagnosis & $\begin{array}{l}\text { - Definite FH } \\
\text { - Probable FH } \\
\text { - Possible FH } \\
\text { - Unlikely FH }\end{array}$ & $\begin{array}{l}\text { - Definite FH } \\
\text { - Possible FH }\end{array}$ & - With FH & - With FH \\
\hline Pros & $\begin{array}{l}\text { - Each criterion is } \\
\text { weighted } \\
\text { - Higher specificity than } \\
\text { MEDPED }\end{array}$ & $\begin{array}{l}\text { - Higher specificity than } \\
\text { MEDPED criteria }\end{array}$ & $\begin{array}{l}\text { - Higher sensitivity than } \\
\text { DLCNC }\end{array}$ & $\begin{array}{l}\text { - High specificity and } \\
\text { sensitivity in Japanese } \\
\text { population }\end{array}$ \\
\hline Cons & $\begin{array}{l}\text { - Not applicable to children } \\
\text { - Lower sensitivity than } \\
\text { MEDPED criteria }\end{array}$ & $\begin{array}{l}\text { - Lower sensitivity than } \\
\text { MEDPED criteria }\end{array}$ & $\begin{array}{l}\text { Without regard to physical } \\
\text { symptoms and a history } \\
\text { of premature CVD } \\
\text { - Lower specificity than } \\
\text { DLCNC and Simon } \\
\text { Broome diagnostic criteria }\end{array}$ & \\
\hline
\end{tabular}

Abbreviations: CVD = cardiovascular disease; DLCNC = Dutch Lipid Clinic Network Criteria; FH = familial hypercholesterolaemia; HeFH = heterozygous familial hypercholesterolaemia; HoFH = homozygous familial hypercholesterolaemia; LDL-C = low-density lipoprotein cholesterol; MEDPED = Make Early Diagnosis to Prevent Early Deaths

the diagnosis of FH adults in Hong Kong; however, because of lower reported LDL-C levels in local patients with $\mathrm{FH}$, the panel recommended a lower threshold for LDL-C levels indicative of definite $\mathrm{FH}$, probable $\mathrm{FH}$, possible $\mathrm{FH}$, and unlikely $\mathrm{FH} .{ }^{10}$ Secondary causes of increased LDL-C levels, such as hypothyroidism and nephrotic syndrome, should be excluded before considering a diagnosis of $\mathrm{FH}$.

\section{Screening for familial hypercholesterolaemia in adults in Hong Kong}

Universal screening for $\mathrm{FH}$ in adults is not practicable in Hong Kong or in most other countries. General screening for $\mathrm{FH}$ as primary prevention in Hong Kong can be challenging, as it is difficult to convince asymptomatic patients to participate in the screening programme. A regular body check, including measurement of the plasma lipid profile, is becoming more popular in Hong Kong. The panel recommended that greater attention should be given to the cholesterol profile as a routine body check item, together with documentation of family history of $\mathrm{FH}$ and premature $\mathrm{CHD}$; this approach may increase the likelihood of identifying potential index FH cases. The risk of cardiovascular events in patients with $\mathrm{FH}$ largely depends on the plasma LDL-C level; however, other risk factors, such as smoking, hypertension, diabetes, and elevated levels of lipoprotein(a) [Lp(a)], are also important. Targeted LDL-C screening in high-risk patients, especially younger patients with premature CHD, is encouraged.

The panel recommended that adults with a plasma LDL-C level $>5 \mathrm{mmol} / \mathrm{L}$ should be regarded as potential probands. For patients at high risk of $\mathrm{FH}$, such as patients with a family history of $\mathrm{FH}$ or premature CHD, the LDL-C level threshold could be $4.5 \mathrm{mmol} / \mathrm{L}$. Tendon xanthomata, arcus cornealis, and tuberous xanthoma or xanthelasma are typically observed in patients with $\mathrm{FH}$ who exhibit very high LDL-C levels. Xanthelasma and arcus cornealis are not specific clinical signs for $\mathrm{FH}$. Tendon xanthomas are more specific for $\mathrm{FH}$ and occur in patients with markedly elevated LDL-C levels (typically $>7.0$ $\mathrm{mmol} / \mathrm{L}$ ); these are rarely present before adulthood in patients with $\mathrm{HeFH}$. They can also occur in patients with sitosterolaemia and cerebrotendinous xanthomatosis.

Cascade screening for relatives of patients with $\mathrm{FH}$ is recommended in both the private and public sectors. Although this may be challenging in the private sector due to financial constraints, cascade 
screening is the most cost-effective approach for the identification of new patients with $\mathrm{FH}$; moreover, it is recommended by international and national bodies, such as the European Atherosclerosis Society and the American Heart Association., ${ }^{1,5}$ The relatives of patients with FH can be screened with a combination of plasma lipid profiles and genetic testing. If the causative mutation is unknown or genetic testing is unavailable, screening can be performed by using plasma lipid profiles alone. Currently, a potential patient with $\mathrm{FH}$ must wait several months for counselling and genetic testing in the public sector (ie, the Hong Kong Department of Health Clinical Genetic Service) and the cost of genetic testing may not be covered by the public health care system.

Genetic testing may not always be necessary or cost-effective. Patients with high LDL-C levels typically must be treated, regardless of the genetic test results; notably, these test results may not substantially alter treatment strategies. Although there may not be great advantages to genetic testing, there are potential benefits in genotyping. ${ }^{17}$ For similar LDL-C levels, the risk of cardiovascular events is greater in patients with $\mathrm{FH}$ than in those without, due to their lifelong exposure to high LDL-C levels since birth. Treatment may not be necessary in patients with $\mathrm{FH}$ who have mildly elevated LDL-C levels. In contrast, long-term follow-up is necessary in patients with $\mathrm{FH}$ who have similar LDL-C levels. With the increasing affordability of genetic testing, the resulting genetic information will help improve the precision of diagnosis and management of FH.

\section{Screening for familial hypercholesterolaemia in children in Hong Kong}

Universal screening of plasma cholesterol levels in children has been proposed in some Western countries, including Australia ${ }^{18}$ and the US. ${ }^{19,20}$ Early diagnosis can lead to effective treatment with lifestyle modification and pharmacotherapy, as appropriate. By reducing the lifetime exposure to LDL-C from an early age, these patients experience substantial benefits in terms of CVD prevention. Thus, universal cholesterol screening in children is more costeffective than identical screening in younger or older adults. Although it is expensive, universal cholesterol screening in childhood may offer the best and most effective strategy for diagnosing $\mathrm{FH} .{ }^{18}$ The paediatric panel agreed that universal screening should target all citizens below 20 years of age, ideally before puberty; moreover, it should identify potential cases of $\mathrm{FH}$ based on age- and gender-specific plasma LDL-C levels.

Cascade screening is highly recommended in children with elevated LDL-C levels and in children with relatives who exhibit $\mathrm{FH}$ phenotypes. Children with a relevant family history and an LDL-C level $>3.6 \mathrm{mmol} / \mathrm{L}$ are likely to have $\mathrm{FH}$. In a local survey of Chinese adolescents in Hong Kong (median [interquartile range] age, 16 [14-17] years), the mean (standard deviation) LDL-C level was 2.15 (0.60) $\mathrm{mmol} / \mathrm{L}$ in boys and $2.24(0.61) \mathrm{mmol} / \mathrm{L}$ in girls; thus, the 95th percentile would be approximately $3.4 \mathrm{mmol} / \mathrm{L} .{ }^{21}$ In children with a plasma LDL-C level $>4.9 \mathrm{mmol} / \mathrm{L}$ and/or physical signs (eg, xanthomata), FH is likely; these children should be screened at any age, as soon as they are identified. Because $\mathrm{FH}$ and sitosterolaemia share several clinical characteristics, sitosterolaemia should also be considered in these patients, especially if both parents appear to exhibit normal lipid levels. Sitosterolaemia can be identified by measuring the plasma levels of plant sterols; the genetic defect can be detected by sequencing the genes for the ABCG5 and ABCG8 transporters. ${ }^{22}$ After consideration of international recommendations and the increasingly early age of acquisition of other risk factors, including obesity and diabetes, in our local population, the paediatric panel suggested a screening age of 5 to 10 years to identify FH; moreover, the panel suggested that a lower threshold for LDL-C levels should be used in children, relative to that used in adults. The paediatric panel also agreed that genetic testing, if available, should be provided for all children who are suspected to have FH, after counselling. Genetic testing would be particularly useful in children whose LDL-C levels are not sufficiently high to make a definite diagnosis of $\mathrm{FH}$ when a mutation has been detected in an affected parent or sibling. Genetic counselling should be provided to the family before undergoing genetic testing to ensure a clear understanding of the implications of such tests.

Despite these recommendations, the panel emphasised that additional surveys are required regarding the distribution of plasma cholesterol levels among local children, in order to improve the screening strategy for $\mathrm{FH}$ in children.

\section{Management of familial hypercholesterolaemia}

\section{Target plasma low-density lipoprotein cholesterol levels}

The prognosis of FH largely depends on the plasma LDL-C levels; these should be maintained as low as possible. The panel suggested that, for primary prevention of CHD, the target LDL-C level for Hong Kong Chinese patients with $\mathrm{FH}$ should be $<2.5 \mathrm{mmol} / \mathrm{L}$. The panel agreed that patients with established atherosclerotic CVD or other cardiovascular risk factors, such as diabetes, elevated $\mathrm{Lp}$ (a) level $\geq 50 \mathrm{mg} / \mathrm{dL}$, pretreatment LDL-C level $\geq 6.72 \mathrm{mmol} / \mathrm{L}$, family history of premature CHD, or advanced age, should be considered as very high 
risk. For very-high-risk patients, the target LDL-C level should be $<1.8 \mathrm{mmol} / \mathrm{L}$; for paediatric patients ( $>10$ years of age) with $\mathrm{FH}$, the panel recommended that the target LDL-C level should be $<3.4 \mathrm{mmol} / \mathrm{L}$.

\section{Detection of atherosclerosis}

The detection of atherosclerosis should begin by taking a complete medical history and performing a thorough physical examination. If the patient is suspected to have atherosclerotic CVD, it may be appropriate to refer them to a cardiologist or other appropriate specialist for further investigation. Computed tomographic coronary angiography is a useful and non-invasive tool to detect coronary atherosclerosis and determine CVD risk. Stress echocardiography can be used to assess myocardial functional capacity and the possibility of silent ischaemia. Carotid ultrasound imaging is noninvasive and can identify early-stage atherosclerosis; it can be used to assess carotid artery disease, predict the risk of stroke, and determine the requirement for intensive treatment in patients with FH. The ankle-brachial index is a useful diagnostic test for early peripheral arterial disease and has been shown to predict CVD and all-cause death in Chinese populations..$^{23,24}$ Pulse wave velocity is a non-invasive measure of arterial stiffness which also correlates with cardiovascular events, such as the development of CHD.

\section{Lifestyle and behaviour modification}

All patients with a clinical diagnosis of $\mathrm{FH}$ should be counselled on lifestyle modification, particularly healthy eating, regular exercise and physical activity, weight control, and cessation of smoking.

\section{Pharmacotherapy}

First-line treatment for hypercholesterolaemia for reducing the risk of CHD involves the use of 3-hydroxy-3-methylglutaryl coenzyme A reductase inhibitors or statins, which significantly reduce the risk of CVD and progression of atherosclerosis in FH. In a long-term cohort study involving more than 2000 patients with $\mathrm{FH}$ without prevalent $\mathrm{CHD}$ in the Netherlands, patients treated with statins showed a $76 \%$ risk reduction (hazard ratio $=0.24 ; 95 \%$ confidence interval $=0.18-0.30 ; \mathrm{P}<0.001$ ) for $\mathrm{CHD}$ compared with untreated patients. ${ }^{25}$ In patients with $\mathrm{HoFH}$, statin-treated patients showed a $66 \%$ reduction in all-cause mortality and $51 \%$ reduction in major cardiovascular events compared with statin-naive patients; however, the mean reduction in LDL-C level was only $26.4 \%$ with lipid-lowering therapy. ${ }^{26}$

A recent Mendelian randomisation analysis revealed that prolonged exposure to lower LDL-C levels, beginning early in life, reduced the risk of CHD by three-fold, when compared with the risk reduction achieved by lowering LDL-C level with a statin started later in life. ${ }^{27}$ The European Atherosclerosis Society Consensus Panel recommended early detection (from age 5 years, or earlier if $\mathrm{HoFH}$ is suspected) in children; the panel suggested lifestyle modification and statin therapy for the treatment of children with $\mathrm{FH}$, as early as age 8 to 10 years. ${ }^{6}$

Typically, adult patients with $\mathrm{FH}$ should be treated with high-intensity statin therapy. Female patients should be advised that statins are contraindicated during pregnancy and should be avoided during lactation. ${ }^{5}$ If the target LDL-C level cannot be achieved with statin monotherapy, a combination therapy with concurrent ezetimibe and/or a bile-acid sequestrant or niacin can be considered. Generally, $\mathrm{Lp}$ (a) levels are increased in patients with $\mathrm{FH},{ }^{28}$ and are considered an independent predictor of CHD in $\mathrm{FH}$ after adjustment for other modifiable risk factors. ${ }^{1,29,30}$ It is desirable to measure the Lp(a) level if the assay is available. Niacin can reduce plasma Lp(a) levels by $30 \%$ to $40 \%$; notably, the LDL-C level lowering-effect of niacin is largely dependent on baseline LDL-C levels. ${ }^{31,32}$ Therefore, if available, niacin may be used in patients with $\mathrm{FH}$ who do not reach their target LDL-C levels with statin therapy. Lipoprotein apheresis will also reduce Lp(a) level, but is not readily available in the public hospitals in Hong Kong; however, plasmapheresis is currently used.

In Hong Kong, statins are the main therapy for paediatric patients with $\mathrm{FH}$. All available statins are approved for use in patients with $\mathrm{HeFH}$ aged $\geq 10$ years (Table $2^{33}$ ). However, in exceptional circumstances, such as when there is a family history of premature $\mathrm{CHD}$, statins are used before age 10 years, as recommended by the guidelines from the United Kingdom National Institute for Health and Care Excellence. ${ }^{34}$ A 2017 Cochrane review analysed nine randomised controlled trials comparing the efficacy and safety of statins versus placebo in 1177 children with $\mathrm{FH}$ aged 6 to 18 years; the authors concluded that statins seem to be safe in the short term, but long-term safety remains unknown. ${ }^{35}$

Patients are initially treated with the lowest doses, which can be increased as necessary. Some patients are prescribed bile acid sequestrants (eg, colestyramine) as early as age 1 year, and ezetimibe at age $\geq 10$ years (Table $2^{33}$ ). Plasmapheresis is reserved for patients with severe disease uncontrolled by conventional therapy. It should be emphasised that lifestyle interventions should be the first-line treatment for paediatric patients with $\mathrm{FH}$; they should not be disregarded, even if pharmacotherapy is used.

\section{Emerging therapies}

Monoclonal antibodies to PCSK9 have emerged as 
TABLE 2. Oral lipid-lowering drugs approved for use in children or adolescents in Hong Kong ${ }^{33}$

\begin{tabular}{|c|c|c|}
\hline Drug & $\begin{array}{l}\text { Indicated age for children or } \\
\text { adolescents }\end{array}$ & Dosage \\
\hline Atorvastatin & $\mathrm{HeFH}, 10-17$ years & $\begin{array}{l}\text { Initial: } 10 \mathrm{mg} \text { once daily } \\
\text { Max: } 20 \mathrm{mg} \text { once daily } \\
\text { Adjustment should be made at intervals } \geq 4 \text { weeks }\end{array}$ \\
\hline Ezetimibe & $\geq 10$ Years & $10 \mathrm{mg}$ once daily \\
\hline Fluvastatin & $\mathrm{HeFH}, \geq 9$ years & $\begin{array}{l}\text { Initial: } 20 \mathrm{mg} \text {. May be adjusted at } 6 \text {-week intervals } \\
\text { Max: } 40 \mathrm{mg} \text { twice daily/80 mg once daily }\end{array}$ \\
\hline Rosuvastatin & $\begin{array}{l}\text { HeFH, 10-17 years } \\
\mathrm{HoFH}\end{array}$ & $\begin{array}{l}\text { Initial: } 5-20 \mathrm{mg} \text { once daily } \\
\text { Max: } 20 \mathrm{mg} \text { once daily } \\
\text { Initial: } 20 \mathrm{mg} \text { once daily }\end{array}$ \\
\hline Simvastatin & $\mathrm{HeFH}, 10-17$ years & Initial: 10 mg once daily \\
\hline Pravastatin & $\begin{array}{l}\mathrm{HeFH} \\
\text { - } 8-13 \text { Years } \\
\text { - } 14-18 \text { Years }\end{array}$ & $\begin{array}{l}\text { Max: } 40 \mathrm{mg} \text { once daily } \\
\text { - } 10-20 \mathrm{mg} \text { once daily } \\
\text { - } 10-40 \mathrm{mg} \text { once daily }\end{array}$ \\
\hline Colestyramine & Hyperlipidaemia, 6-12 years & $\begin{array}{l}240 \mathrm{mg} / \mathrm{kg} \text { daily in } 2-3 \text { divided doses or calculated as percentage } \\
\text { of the adult }(70 \mathrm{~kg}) \text { dose } \\
\text { Max: } 8 \mathrm{~g} \text { once daily }\end{array}$ \\
\hline
\end{tabular}

Abbreviations: $\mathrm{HeFH}=$ heterozygous familial hypercholesterolaemia; $\mathrm{HoFH}=$ homozygous familial hypercholesterolaemia

the most promising treatment option for patients with FH. This class of agents, given by subcutaneous injection once or twice monthly, reduced LDL-C levels by $50 \%$ to $70 \%$ in patients with $\mathrm{HeFH}$ who were treated with statins with or without ezetimibe, ${ }^{36,37}$ as well as in patients with primary hypercholesterolaemia with or without statin therapy. ${ }^{38,39}$ Two PCSK9 inhibitors, alirocumab (previously known as REGN727 and SAR236553, Sanofi and Regeneron Pharmaceuticals, Inc) and evolocumab (AMG-145, Amgen) were approved by the US Food and Drug Administration (FDA) and European Medicines Agency in 2015 for their proven efficacy in reducing LDL-C levels in patients at risk for CVD; these drugs are available in Hong Kong. By using this group of drugs, very low LDL-C levels $(\mathrm{eg},<1.0 \mathrm{mmol} / \mathrm{L}) \mathrm{can}$ be achieved in patients with $\mathrm{HeFH}$.

Mipomersen is an apoB antisense oligonucleotide which inhibits the biosynthesis of apoB, thus reducing hepatic very low-density lipoprotein cholesterol (VLDL-C) production and secretion. ${ }^{40}$ In clinical trials, subcutaneous injection of mipomersen reduced plasma LDL-C levels by $25 \%$ and $28 \%$ in patients with $\mathrm{HoFH}^{41}$ and $\mathrm{HeFH},{ }^{42}$ respectively. The major side-effects of mipomersen include frequent injection site reactions, short-lived fatigue and myalgia, hepatic steatosis, and elevations in plasma aminotransferases. These hepatic changes typically resolve upon drug discontinuation. Mipomersen is not available in Hong Kong.

Lomitapide is an orally available microsomal triglyceride transfer protein inhibitor which decreases the hepatic production and secretion of VLDL-C. Lomitapide has been approved for the treatment of
HoFH in the US and Europe as an add-on therapy. In a multi-centre study of patients with $\mathrm{HoFH}$, lomitapide reduced LDL-C levels by $50 \%, 44 \%$, and $38 \%$ at 26,56 , and 78 weeks, respectively. ${ }^{43}$ However, lomitapide may increase plasma aminotransferases and intrahepatic fat content. Lomitapide is not available in Hong Kong. Both mipomersen and lomitapide work via pathways independent of the LDLR and are effective in patients with HoFH who exhibit null mutations. These two drugs have been approved by the FDA for use in patients with $\mathrm{HoFH}$.

\section{Conclusion}

Patients with $\mathrm{FH}$ remain underdiagnosed and undertreated in Hong Kong. Increased awareness, early identification, and optimal treatment are essential to reduce the risk of premature CHD, thereby restoring decades of healthy, normal life in patients with FH. Developing a model of care for $\mathrm{FH}$ in Hong Kong will help to bridge the gap in prevention of CVD and improve outcomes in patients with $\mathrm{FH}$. Action is needed to collect more population-based data to further guide recommendations and the development of models of care for the management of FH. While these data are gathered, this consensus statement aims to serve as a guide to inform clinical practice and future research.

\section{Supplementary information}

Online supplementary information (Appendix) is available for this article at www.hkmj.org.

\section{Author contributions}

All authors have made substantial contributions to the expert 
panel consensus viewpoint and provided critical revision for important intellectual content. B Tomlinson is responsible for drafting of the article.

\section{Acknowledgement}

The expert panel thanks Sanofi-Aventis Hong Kong Limited for supporting the organisation of the meetings and providing editorial assistance in preparing the statement by an unrestricted educational grant.

\section{Funding/support}

The meetings during which this consensus statement was formulated and some editorial assistance in preparing the manuscript were funded by an unrestricted educational grant from Sanofi-Aventis Hong Kong Limited. The funder had no role in determining the content of the expert panel consensus statement.

\section{Declaration}

All authors have disclosed no conflicts of interest. All authors had full access to the data, contributed to the study, approved the final version for publication, and take responsibility for its accuracy and integrity.

\section{References}

1. Nordestgaard BG, Chapman MJ, Humphries SE, et al. Familial hypercholesterolaemia is underdiagnosed and undertreated in the general population: guidance for clinicians to prevent coronary heart disease: consensus statement of the European Atherosclerosis Society. Eur Heart J 2013;34:3478-90a.

2. Hovingh GK, Davidson MH, Kastelein JJ, O'Connor AM. Diagnosis and treatment of familial hypercholesterolaemia. Eur Heart J 2013;34:962-71.

3. Reiner Ž. Management of patients with familial hypercholesterolaemia. Nat Rev Cardiol 2015;12:565-75.

4. Cuchel M, Bruckert E, Ginsberg HN, et al. Homozygous familial hypercholesterolaemia: new insights and guidance for clinicians to improve detection and clinical management. A position paper from the Consensus Panel on Familial Hypercholesterolaemia of the European Atherosclerosis Society. Eur Heart J 2014;35:2146-57.

5. Gidding SS, Champagne MA, de Ferranti SD, et al. The agenda for familial hypercholesterolemia: a scientific statement from the American Heart Association Circulation 2015;132:2167-92.

6. Wiegman A, Gidding SS, Watts GF, et al. Familia hypercholesterolaemia in children and adolescents: gaining decades of life by optimizing detection and treatment. Eur Heart J 2015;36:2425-37.

7. Harada-Shiba M, Arai H, Oikawa S, et al. Guidelines for the management of familial hypercholesterolemia. J Atheroscler Thromb 2012;19:1043-60.

8. Pang J, Sullivan DR, Harada-Shiba M, et al. Significant gaps in awareness of familial hypercholesterolemia among physicians in selected Asia-Pacific countries: a pilot study. J Clin Lipidol 2015;9:42-8.

9. Pang RW, Tam S, Janus ED, et al. Plasma lipid, lipoprotein and apolipoprotein levels in a random population sample of 2875 Hong Kong Chinese adults and their implications (NCEP ATP-III, 2001 guidelines) on cardiovascular risk assessment. Atherosclerosis 2006;184:438-45.
10. Hu M, Lan W, Lam CW, Mak YT, Pang CP, Tomlinson B. Heterozygous familial hypercholesterolemia in Hong Kong Chinese. Study of 252 cases. Int J Cardiol 2013;167:762-7.

11. O'Donnell MJ, Xavier D, Liu L, et al. Risk factors for ischaemic and intracerebral haemorrhagic stroke in 22 countries (the INTERSTROKE study): a case-control study. Lancet 2010;376:112-23.

12. Scientific Steering Committee on behalf of the Simon Broome Register Group. Risk of fatal coronary heart disease in familial hypercholesterolaemia. BMJ 1991;303:893-6.

13. Williams RR, Hunt SC, Schumacher MC, et al. Diagnosing heterozygous familial hypercholesterolemia using new practical criteria validated by molecular genetics. Am J Cardiol 1993;72:171-6.

14. Civeira F, International Panel on Management of Familial Hypercholesterolemia. Guidelines for the diagnosis and management of heterozygous familial hypercholesterolemia. Atherosclerosis 2004;173:55-68.

15. Damgaard D, Larsen ML, Nissen PH, et al. The relationship of molecular genetic to clinical diagnosis of familial hypercholesterolemia in a Danish population. Atherosclerosis 2005;180:155-60.

16. Harada-Shiba M, Arai H, Okamura T, et al. Multicenter study to determine the diagnosis criteria of heterozygous familial hypercholesterolemia in Japan. J Atheroscler Thromb 2012;19:1019-26.

17. Nordestgaard BG, Benn M. Genetic testing for familial hypercholesterolaemia is essential in individuals with high LDL cholesterol: who does it in the world? Eur Heart J 2017;38:1580-3

18. Pang J, Martin AC, Mori TA, Beilin LJ, Watts GF. Prevalence of familial hypercholesterolemia in adolescents: potential value of universal screening? J Pediatr 2016;170:315-6.

19. Kwiterovich PO, Gidding SS. Universal screening of cholesterol in children. Clin Cardiol 2012;35:662-4.

20. Expert panel on integrated guidelines for cardiovascular health and risk reduction in children and adolescents: summary report. Pediatrics 2011;128(Suppl 5):S213-56.

21. Kong AP, Choi KC, Ko GT, et al. Associations of overweight with insulin resistance, beta-cell function and inflammatory markers in Chinese adolescents. Pediatr Diabetes 2008;9:488-95.

22. Hu M, Yuen YP, Kwok JS, Griffith JF, Tomlinson B. Potential effects of NPC1L1 polymorphisms in protecting against clinical disease in a Chinese family with sitosterolaemia. J Atheroscler Thromb 2014;21:989-95.

23. Hong Kong Diabetes Registry, Yang X, So WY, et al. Development and validation of an all-cause mortality risk score in type 2 diabetes. Arch Intern Med 2008;168:451-7.

24. Luo YY, Li J, Xin Y, Zheng LQ, Yu JM, Hu DY. Risk factors of peripheral arterial disease and relationship between low ankle brachial index and mortality from all-cause and cardiovascular disease in Chinese patients with hypertension. J Hum Hypertens 2007;21:461-6.

25. Versmissen J, Oosterveer DM, Yazdanpanah $M$, et al. Efficacy of statins in familial hypercholesterolaemia: a long term cohort study. BMJ 2008;337:a2423.

26. Raal FJ, Pilcher GJ, Panz VR, et al. Reduction in mortality in subjects with homozygous familial hypercholesterolemia associated with advances in lipid-lowering therapy. Circulation 2011;124:2202-7.

27. Ference BA, Yoo W, Alesh I, et al. Effect of long-term exposure to lower low-density lipoprotein cholesterol 
beginning early in life on the risk of coronary heart disease: a Mendelian randomization analysis. J Am Coll Cardiol 2012;60:2631-9.

28. Langsted A, Kamstrup PR, Benn M, Tybjærg-Hansen A, Nordestgaard BG. High lipoprotein(a) as a possible cause of clinical familial hypercholesterolaemia: a prospective cohort study. Lancet Diabetes Endocrinol 2016;4:57787.

29. Alonso R, Andres E, Mata N, et al. Lipoprotein(a) levels in familial hypercholesterolemia: an important predictor of cardiovascular disease independent of the type of LDL receptor mutation. J Am Coll Cardiol 2014;63:1982-9.

30. Chan DC, Pang J, Hooper AJ, et al. Elevated lipoprotein(a), hypertension and renal insufficiency as predictors of coronary artery disease in patients with genetically confirmed heterozygous familial hypercholesterolemia. Int J Cardiol 2015;201:633-8.

31. $\mathrm{Hu} \mathrm{M}$, Tomlinson B. Niacin for reduction of cardiovascular risk. N Engl J Med 2014;371:1941-2.

32. Hu M, Yang YL, Ng CF, et al. Effects of phenotypic and genotypic factors on the lipid responses to niacin in Chinese patients with dyslipidemia. Medicine (Baltimore) 2015;94:e881.

33. Monthly Index of Medical Specialities. Available from: http://www.mims.com/hongkong. Accessed 1 Aug 2017.

34. National Institute for Health and Clinical Excellence. Familial hypercholesterolaemia: identification and management. 2008. Available from: https://www. nice.org.uk/guidance/cg71/resources/familialhypercholesterolaemia-identification-and-managementpdf-975623384005. Accessed 1 Feb 2016.

35. Vuorio A, Kuoppala J, Kovanen PT, et al. Statins for children with familial hypercholesterolemia. Cochrane Database Syst Rev 2017;(7):CD006401.

36. Stein EA, Gipe D, Bergeron J, et al. Effect of a monoclonal antibody to PCSK9, REGN727/SAR236553, to reduce low-density lipoprotein cholesterol in patients with heterozygous familial hypercholesterolaemia on stable statin dose with or without ezetimibe therapy: a phase 2 randomised controlled trial. Lancet 2012;380:29-36.

37. Stein EA, Honarpour N, Wasserman SM, Xu F, Scott R, Raal FJ. Effect of the proprotein convertase subtilisin/kexin 9 monoclonal antibody, AMG 145, in homozygous familial hypercholesterolemia. Circulation 2013;128:2113-20.

38. McKenney JM, Koren MJ, Kereiakes DJ, Hanotin C, Ferrand AC, Stein EA. Safety and efficacy of a monoclonal antibody to proprotein convertase subtilisin/kexin type 9 serine protease, SAR236553/REGN727, in patients with primary hypercholesterolemia receiving ongoing stable atorvastatin therapy. J Am Coll Cardiol 2012;59:2344-53.

39. Stein EA, Mellis S, Yancopoulos GD, et al. Effect of a monoclonal antibody to PCSK9 on LDL cholesterol. N Engl J Med 2012;366:1108-18.

40. Visser ME, Witztum JL, Stroes ES, Kastelein JJ. Antisense oligonucleotides for the treatment of dyslipidaemia. Eur Heart J 2012;33:1451-8.

41. Raal FJ, Santos RD, Blom DJ, et al. Mipomersen, an apolipoprotein B synthesis inhibitor, for lowering of LDL cholesterol concentrations in patients with homozygous familial hypercholesterolaemia: a randomised, doubleblind, placebo-controlled trial. Lancet 2010;375:998-1006.

42. Stein EA, Dufour R, Gagne C, et al. Apolipoprotein B synthesis inhibition with mipomersen in heterozygous familial hypercholesterolemia: results of a randomized, double-blind, placebo-controlled trial to assess efficacy and safety as add-on therapy in patients with coronary artery disease. Circulation 2012;126:2283-92.

43. Cuchel M, Blom DJ, Averna MR. Clinical experience of lomitapide therapy in patients with homozygous familial hypercholesterolaemia. Atheroscler Suppl 2014;15:33-45. 